\title{
Modelling of the precise movement of a ship at slow speed to minimize the trajectory deviation risk
}

\author{
J. Malecki \\ Polish Naval Academy, \\ Poland Faculty of Mechanics and Electrical Engineering, Poland
}

\begin{abstract}
In this paper, soft computing techniques applied to designing an autopilot enabling the control of the precise movement of a hydrographic ship in a horizontal plane along the desired trajectory have been considered. The reference trajectory is determined by particular way-points, and command signals are generated by independent fuzzy controllers. The minimization of the risk of deviating from the trajectory has been considered as a function of control quality in an environment with, and without, disturbances. With the aim of presenting the tests' effectiveness and robustness, selected results of the executed simulation have been presented.
\end{abstract}

Keywords: precise control, slow speed of ship, minimisation of deviation risk, artificial intelligence.

\section{Introduction}

Modelling of a safe ship's movement with the aid of soft computing techniques, and considering all real conditions of operation, is a complicated process due to problems with the evaluation of coefficients of dynamics, the description of external forces and sea environmental disturbances. A hydrographic ship has been considered as a control plant [6].

Contemporary ships are often equipped with control systems allowing for complex manoeuvres and operation execution. The process of a ship's automatic control is a difficult task due to its nonlinear dynamics. Moreover, the dynamics can change according to the modification of the drive's configuration, which is suited to the executed task of ship [2]. 
Nowadays fuzzy systems in control of special ship motions find wide practical applications, ranging from soft regulatory control in consumer products to accurate control and modelling of complex nonlinear systems. In this work use of the fuzzy autopilot in control of a ship movement has been proposed [4].

The paper has been organized in the following way: it starts with a brief description of the dynamical and kinematical equations of ship motion. Then the problem of motion along predefined trajectory has been discussed. Next, fuzzy control law has been described and the results of simulation tests have been inserted. Finally, selected conclusions have been presented.

\section{Modelling of precise ship movement - equations of motion}

General movement of a ship in 6 degrees of freedom (DOF) is described with the aid of the following vectors $[2,3,6]$ :

$$
\begin{aligned}
\eta & =[x, y, z, \Phi, \Theta, \Psi]^{T} \\
v & =[u, v, w, p, q, r]^{T} \\
\tau & =[X, Y, Z, K, M, N]^{T}
\end{aligned}
$$

where:
$\eta$
vector of position and orientation in the earth-fixed frame;
$x, y, z$ coordinates of position;
$\Phi, \Theta, \Psi$ coordinates of orientation;
$v$
$u, v, w$ vector of linear and angular velocities in the body-fixed frame;
$p, q, r$ linear

$p, q, r$
$\tau$ angular velocities about longitudinal, transversal and vertical axes;
$X, Y, Z$ vector of forces and moments acting on the ship in the body-fixed frame;
$K, M, N$ forces along longitudinal, transversal and vertical axes; moments about longitudinal, transversal and vertical axes.

Simplified equations of ship's precise motion are described in following form [6]:

$$
\begin{array}{r}
m\left[\dot{u}-v r+w q-x_{G}\left(q^{2}+r^{2}\right)+y_{G}(p q-\dot{r})+z_{G}(p r+\dot{q})\right]=X \\
m\left[\dot{v}-w p+u r-y_{G}\left(r^{2}+p^{2}\right)+z_{G}(q r-\dot{p})+x_{G}(q p+\dot{r})\right]=Y \\
I_{z} \dot{r}+\left(I_{y}-I_{x}\right) p q-(\dot{q}+r p) I_{y z}+\left(q^{2}-p^{2}\right) I_{x y}+(r q-\dot{p}) I_{z x} \\
+m\left[x_{G}(\dot{v}-w p+u r)-y_{G}(\dot{u}-v r+w q)\right]=N
\end{array}
$$


In general dynamical and kinematical equations of motion $[1,2]$ can be expressed in following form $[3,5,6]$ :

$$
\begin{aligned}
& \mathbf{M} \dot{\mathbf{v}}+\mathbf{C}(\mathbf{v}) \mathbf{v}+\mathbf{D}(\mathbf{v}) \mathbf{v}+\mathbf{g}(\boldsymbol{\eta})=\boldsymbol{\tau} \\
& \dot{\boldsymbol{\eta}}=\mathbf{J}(\boldsymbol{\eta}) \mathbf{v}
\end{aligned}
$$

where:
$M \quad$ inertia matrix including a rigid-body and an added mass inertia matrix;
$C$ (v) matrix of Coriolis and centripetal terms including a rigid-body and an added mass Coriolis and centripetal matrixes;
$D(v) \quad$ hydrodynamic damping matrix;
$g(\eta)$ restoring forces and moments matrix;
$J(\eta) \quad$ velocity transformation matrix transforming parameters between body-fixed and earth-fixed coordinate systems.

\section{Precise control of a ship in a horizontal plane}

For the aim of analysis and mathematical description of a ship motion in the horizontal plane, three coordinate systems (fig. 1) have been defined $[3,5,6]$ :

- global coordinate system OXY, also called the earth-fixed coordinate system;

- local coordinate system $\mathrm{O}_{0} \mathrm{X}_{0} \mathrm{Y}_{0}$, fixed to the body of a ship;

- reference coordinate system $\mathrm{WP}_{\mathrm{i}} \mathrm{X}_{\mathrm{i}} \mathrm{Y}_{\mathrm{i}}$ - this system is not fixed.

Precise control system of the ship has been designed under the following assumptions:

- the ship moves with varying linear velocities $u, v$ and the angular velocity $r$;

- coordinates of position $x, y$ and the heading $\Psi$ are measurable;

- the desired trajectory is a broken line defined by set of way-points $\mathrm{WP}_{1}$, $\mathrm{WP}_{2}, \mathrm{WP}_{3}$, etc. with coordinates respectively $\left(x_{1}, y_{1}\right),\left(x_{2}, y_{2}\right),\left(x_{3}, y_{3}\right)$, etc.;

- the command signal consists of three components $\tau=[\mathrm{X}, \mathrm{Y}, \mathrm{N}]$.

It has been assumed that $\mathrm{X}$-axis in the reference coordinate system $\mathrm{WP}_{i} \mathrm{X}_{i} \mathrm{Y}_{i}$ covers with straight line passing through points $\left(x_{i}, y_{i}\right)$ and $\left(x_{i+1}, y_{i+1}\right)$. The reference system can be obtained from the global one as a result of the transformation consisting of movement along the vector $\overline{\mathrm{O}_{0} \mathrm{WP}_{\mathrm{i}}}$ and rotation about Z-axis around the angle $\phi_{i}$.

A main goal of the precise steering system of the ship motion in the horizontal plane is to minimize mean square deviations $\Delta y$ and $\Delta \Psi$ measured in the system $\mathrm{WP}_{i} \mathrm{X}_{i} \mathrm{Y}_{i}$, (fig. 1):

- $\Delta y$ is a perpendicular distance of the ship's centre of gravity to the predefined trajectory;

- $\Delta \Psi$ is a local heading angle defined as the angle between the track reference line and the ship's centreline. 


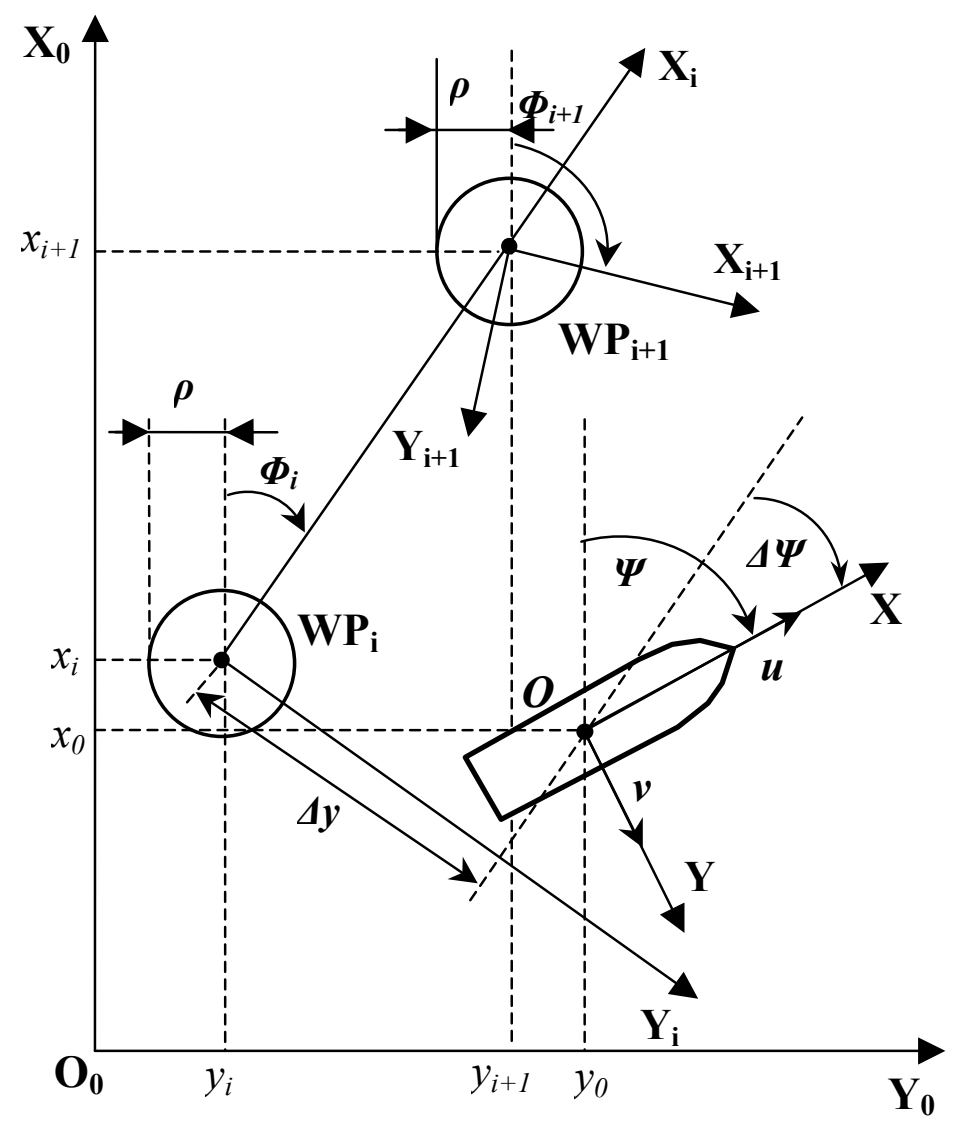

Figure 1: Three coordinate systems used in the description of a ship's motion in the horizontal plane: $\mathrm{O}_{0} \mathrm{X}_{0} \mathrm{Y}_{0}$ - earth-fixed system, $\mathrm{OXY}$ - body-fixed system, and $\mathrm{WP}_{\mathrm{i}} \mathrm{X}_{\mathrm{i}} \mathrm{Y}_{\mathrm{i}}-$ reference system.

The structure of the above control system described is presented in fig. 2 .

The form of an assumed cost function $\mathbf{J}_{\text {cost }}$ describes the following expression:

$$
\mathrm{J}_{\text {cost }}=\min \sum_{t}\left(\lambda_{y} \Delta y^{2}(t)+\lambda_{\Psi} \Delta \Psi^{2}(t)\right)
$$

where:

$$
\Delta y(t)=-\sin \left(\phi_{i}\right)\left(x_{0}(t)-x_{i}\right)+\cos \left(\phi_{i}\right)\left(y_{0}(t)-y_{i}\right)
$$




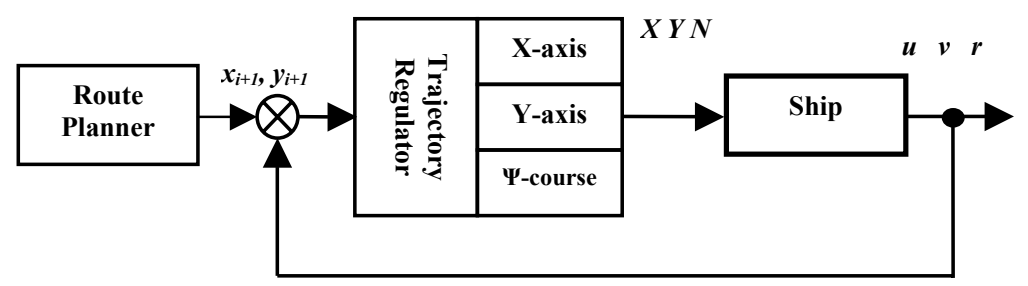

Figure 2: General structure of the control system of the ship.

$$
\begin{array}{ll}
x_{0}(t), y_{0}(t) \quad \begin{array}{l}
\text { instantaneous coordinates of the ship's centre of gravity } \\
\text { in the global system } \mathrm{O}_{0} \mathrm{X}_{0} \mathrm{Y}_{0} ;
\end{array} \\
\begin{array}{ll}
\text { coordinates of the point } \mathrm{WP}_{i} \text { in the system } \mathrm{O}_{0} \mathrm{X}_{0} \mathrm{Y}_{0} ; \\
x_{i}, y_{i}
\end{array} \\
\begin{array}{l}
\text { angle of rotation of the reference coordinate system with } \\
\text { respect to the global one. }
\end{array}
\end{array}
$$

This angle has been described in following form:

$$
\phi_{i}=\arctan \left[\frac{y_{i+1}-y_{i}}{x_{i+1}-x_{i}}\right]
$$

$\Delta \Psi(t)=\Psi(t)-\phi_{i}$,

$$
\begin{array}{ll}
\Psi(t) & \text { instantaneous course of the vehicle in the system } \mathrm{O}_{0} \mathrm{X}_{0} \mathrm{Y}_{0} ; \\
t & \text { time; } \\
\lambda_{y}, \lambda_{\Psi} & \text { constant coefficients. }
\end{array}
$$

Each time the ship location $\left(x_{0}(t), y_{0}(t)\right)$ at the time $t$ satisfies:

$$
\left[x_{i}-x_{0}(t)\right]^{2}+\left[y_{i}-y_{0}(t)\right]^{2} \leq \rho^{2}
$$

here (see fig. 1):

$\rho \quad$ a circle of acceptance, the next way-point should be selected, the reference coordinate system $\mathrm{WP}_{i} \mathrm{X}_{i} \mathrm{Y}_{i}$ changed into $\mathrm{WP}_{i+1} \mathrm{X}_{i+1} \mathrm{Y}_{i+1}$;

$\phi_{i+1} \quad$ an angle of rotation, calculated according to [6].

New ship's position $\left(x_{i+1}, y_{i+1}\right)$ is updated corresponding to new reference coordinate system.

\section{Fuzzy control law}

For the aim of designing of the fuzzy proportional derivative controller (FPD), controller adopted from [6, 7] has been used (fig. 3). 




Figure 3: $\quad$ Fuzzy control structure.

Membership functions of fuzzy sets of input variables are: error signal $e_{k}(t)=\eta_{d k}-\eta_{k}(t)$ and derived change in error $\Delta e_{k}(t)=\eta_{k}(t)-\eta_{k}(t-1)$ and output one (command signal) $\tau_{k}(t)$. Here $k$ is equal to the number of DOF. The notation is taken as follows: $\mathrm{N}$ - negative, $\mathrm{Z}$ - zero, $\mathrm{P}$ - positive, $\mathrm{S}-$ small, $\mathrm{M}$ medium and $\mathrm{B}-$ big.

Table 1 rules presented from the Mac Vicar-Whelan's standard base of rules have been chosen as the control ones [1,7]. The unknown parameters of the proposed fuzzy controllers have been determined with the aid of fuzzy base of knowledge.

Table 1: $\quad$ The fuzzy controller's base of rules.

\begin{tabular}{|c|c|c|c|c|c|c|}
\cline { 3 - 7 } \multicolumn{2}{c|}{} & \multicolumn{5}{c|}{ Error signal $e_{k}$} \\
\cline { 2 - 7 } \multicolumn{2}{c|}{} & NB & NM & Z & PM & PB \\
\hline \multirow{2}{*}{$\begin{array}{c}\text { Derived } \\
\text { change in } \\
\text { error } \Delta e_{k}\end{array}$} & $\mathrm{~N}$ & $\mathrm{NB}$ & $\mathrm{NM}$ & $\mathrm{NS}$ & $\mathrm{Z}$ & $\mathrm{PS}$ \\
\cline { 2 - 7 } & $\mathrm{Z}$ & $\mathrm{NM}$ & $\mathrm{NS}$ & $\mathrm{Z}$ & $\mathrm{PS}$ & $\mathrm{PM}$ \\
\hline
\end{tabular}

\section{Simulation study}

Figures 4 and 5 contain selected results of simulation of studies considered in this article. Simulations of the automatic steering system operation are based on data executed on a real hydrographic ship. Her mathematical model was used to simulate studies in this article [5,6].

The simulated studies of the worked out automatic steering system were executed in the Matlab environment. Forces of thrust generated by mathematical model of the main propulsion ( 2 screw) have been presented in fig. 4. Disturbances of sea environment: wind $5^{\circ} \mathrm{B}$, wave and sea current $1 \mathrm{~m} / \mathrm{s}$ influence on the ship [6]. Fuzzy proportional-derivative controller (PD) was used as a regulator in automatic steering system. The same forces of thrust generated by the main propulsion and bow thruster without influence of disturbances are illustrated in fig. 5. In this case classical proportional-integral-derivative regulator (PID) was used in automatic steering system. 



Figure 4: Automatic steering system of a ship with a fuzzy proportionalderivative regulator $(\mathrm{PD})$. Thrust forces the main propulsion $\mathrm{F}_{\mathrm{s} 1}$, $\mathrm{F}_{\mathrm{s} 2}$ (upper plot) and thrust forces the bow thruster $\mathrm{F}_{\mathrm{ss}}$ (lower plot). 

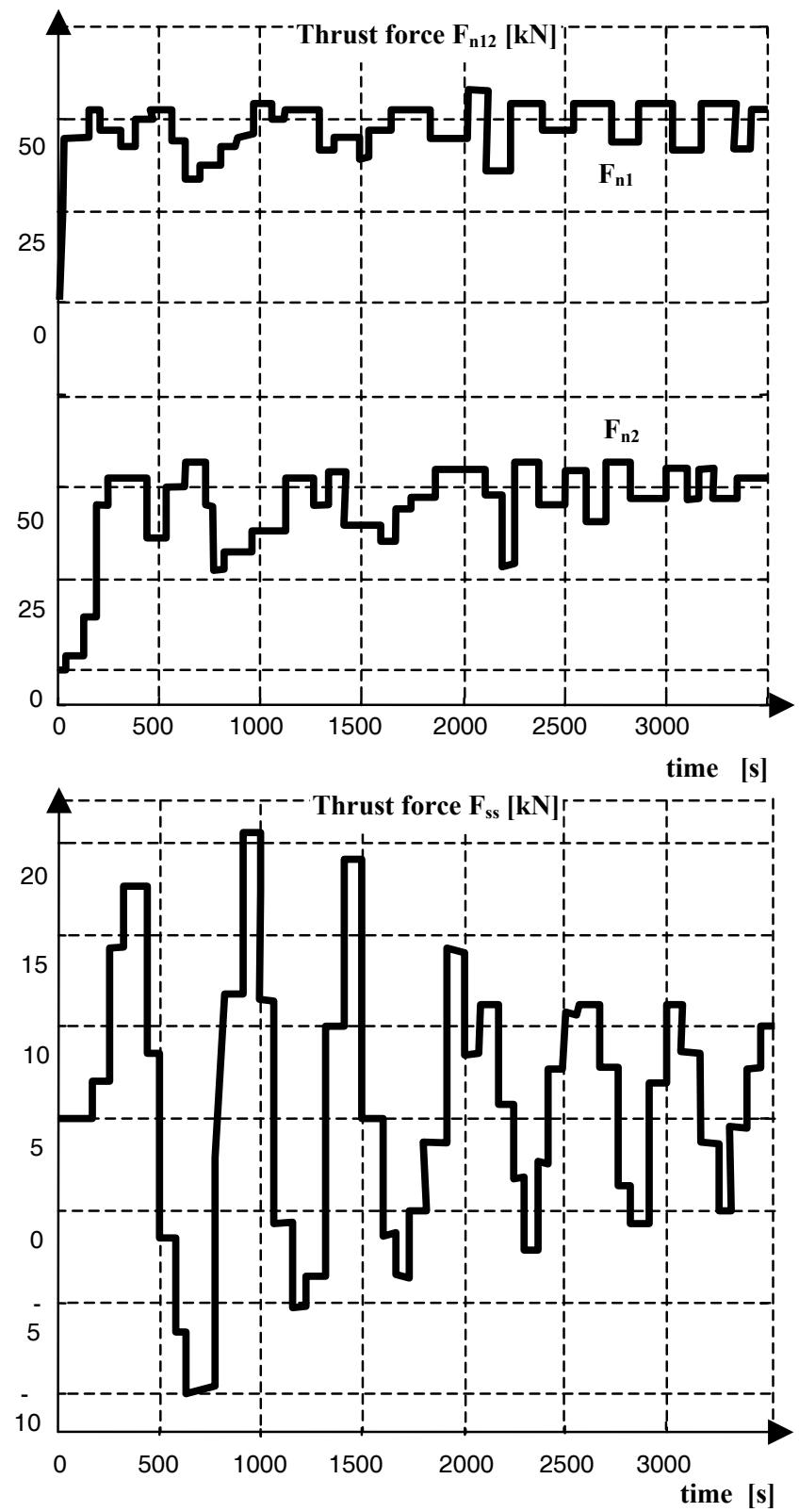

Figure 5: Automatic steering system of ship with a classical proportionalintegral-derivative regulator (PID). Thrust forces the main propulsion $\mathrm{F}_{\mathrm{s} 1}, \mathrm{~F}_{\mathrm{s} 2}$ (upper plot) and thrust forces the bow thruster $\mathrm{F}_{\mathrm{ss}}$ (lower plot). 


\section{Conclusion}

The present state of knowledge associated with problems of designing the fuzzy automatic steering system is formalized in a little degree. This state decides about the effectiveness of working of these types of systems. The effectiveness of their action usually is based on experience and intuition of designer and experience and practical knowledge of the helmsmen and navigators. In the large measure they define the base of the fuzzy algorithm of steering and they decide about the way the control law will describe action of the steered process $[3,6]$. In this work fuzzy regulators including variables with 5 - 7 fuzzy sets were used. Too small a quantity of these sets does not allow the essence of the steering object, however too large a quantity causes the considerable and inconvenient growth of the number of parameters describing the algorithms of steering. Conducted research allows one to state that the use of fuzzy logic to the precise steering of ship movement enables execution of hydrographic tasks with large precision.

In this paper, the use of fuzzy controllers in precise control along a desired trajectory has been described. Results presented of numerical researches prove that an applied approach in designing of autopilots gives positive effects providing the suitable performance of the proposed control system. Another advantage of the control system discussed is its flexibility with regard to the change of dynamic properties of the ships and a performance index.

Further works are needed to identify the best fuzzy structure of the autopilot and to test the robustness of this approach in presence of environmental disturbances.

\section{Acknowledgement}

The present work was partially supported by State Committee for Scientific Research in Poland under Grant no. N504 - O 003332

\section{References}

[1] Driankov, D., Hellendoorn, H., \& Reinfrank, M., An introduction to fuzzy control, Springer-Verlag, 1993.

[2] Fossen, T.I., Marine control systems, Marine Cybernetics AS, New York, 2002.

[3] Garus, J., Using of softcomputing techniques to modelling of motion of underwater robot under conditions of environmental disturbances, Polish Journal of environmental studies, vol. 16, no 4B, pp. 34-27, 2007

[4] Kacprzyk, J., Multistage fuzzy control, John Wiley and Sons, New York, 1997.

[5] Malecki, J., Mathematical model for control of ship at slow speed, Polish Journal of environmental studies, vol. 16, no 4B, pp. 126-129, 2007 
304 Computational Methods and Experimental Measurements XIV

[6] Malecki, J., Mathematical model of ship as object of precise steering, Scientific Magazine Polish Naval Academy, no 169/K, pp. 289-302, Gdynia, 2007 (in Polish).

[7] Yager, R.R., \& Filev, D.P., Essential of fuzzy modelling and control, John Wiley and Sons, 1994. 